\title{
Extended Anterolateral Infralabyrinthine Transjugular Approach for Microsurgical Resection of Giant Glomus Vagale Tumor: Operative Video and Technical Nuances
}

James K. Liu ${ }^{1,2,3}$ Kevin Zhao ${ }^{1}$ Soly Baredes ${ }^{2,3}$ Robert W. Jyung ${ }^{2,3}$

\author{
${ }^{1}$ Department of Neurological Surgery, Rutgers New Jersey Medical \\ School, Neurological Institute of New Jersey, Saint Barnabas Medical \\ Center, Robert Wood Johnson Barnabas Health, Livingston and \\ Newark, New Jersey, United States \\ 2 Department of Otolaryngology-Head and Neck Surgery, Rutgers \\ New Jersey Medical School, Neurological Institute of New Jersey, \\ Saint Barnabas Medical Center, RWJ Barnabas Health, Newark, New \\ Jersey, United States \\ ${ }^{3}$ Center for Skull Base and Pituitary Surgery, Rutgers New Jersey Medical \\ School, Neurological Institute of New Jersey, Saint Barnabas Medical Center, \\ RWJ Barnabas Health, Livington and Newark, New Jersey, United States
}

Address for correspondence James K. Liu, MD, Department of Neurological Surgery, Rutgers New Jersey Medical School, Neurological Institute of New Jersey, Saint Barnabas Medical Center, RWJ Barnabas Health, 90 Bergen Street, Suite 8100, Newark, NJ 07103, United States (e-mail: james.liu.md@rutgers.edu).

J Neurol Surg B 2021;82(suppl S1):S59-S60.

\begin{abstract}
Keywords

- glomus vagale

- paraganglioma

- extended anterolateral approach

- infralabyrinthine transjugular

- skull base surgery

- glomus tumor

Glomus vagale tumor is a paraganglioma of the vagus nerve. It is a rare type of benign tumor that occupies the head and neck and skull base regions. Patients often present with lower cranial nerve dysfunctions such as difficulty swallowing, tongue weakness, and hoarseness. Surgical treatment can be complex and difficult due to its high vascularity, frequent involvement of lower cranial nerves, and surrounding critical vascular structures. In this operative video, we demonstrate an extended anterolateral infralabyrinthine transjugular approach for microsurgical resection of a giant glomus vagale tumor in a 53-year-old male who presented with an enlarging neck mass, difficulty swallowing, right tongue weakness, and hoarseness. Imaging revealed a giant glomus vagale tumor in the right parapharyngeal space extending into the jugular foramen with occlusion of the internal jugular vein. After preoperative embolization, the patient underwent a near-total resection of the tumor with a small microscopic residual at the pars nervosa. In summary, the extended anterolateral infralabyrinthine transjugular approach is a useful strategy for removal of giant glomus vagale tumors extending into the skull base. The surgical technique and nuances are described in a step-by-step fashion in this illustrative operative video.

The link to the video can be found at: https://youtu.be/LOEosQK95LE.
\end{abstract}

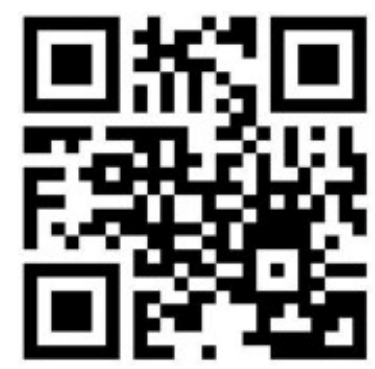

received

June 25,2020

accepted

June 25,2020

published online

November 26, 2020

\section{Conflict of Interest}

None declared.

www.thieme.com/skullbasevideos

www.thieme.com/jnlsbvideos

DOI https://doi.org/

10.1055/s-0040-1716532. ISSN 2193-6331. (c) 2020. The Author(s).

This is an open access article published by Thieme under the terms of the Creative Commons Attribution-NonDerivative-NonCommercial-License, permitting copying and reproduction so long as the original work is given appropriate credit. Contents may not be used for commercial purposes, or adapted, remixed, transformed or built upon. (https://creativecommons.org/ licenses/by-nc-nd/4.0/) Georg Thieme Verlag KG, Rüdigerstraße 14, 70469 Stuttgart, Germany 


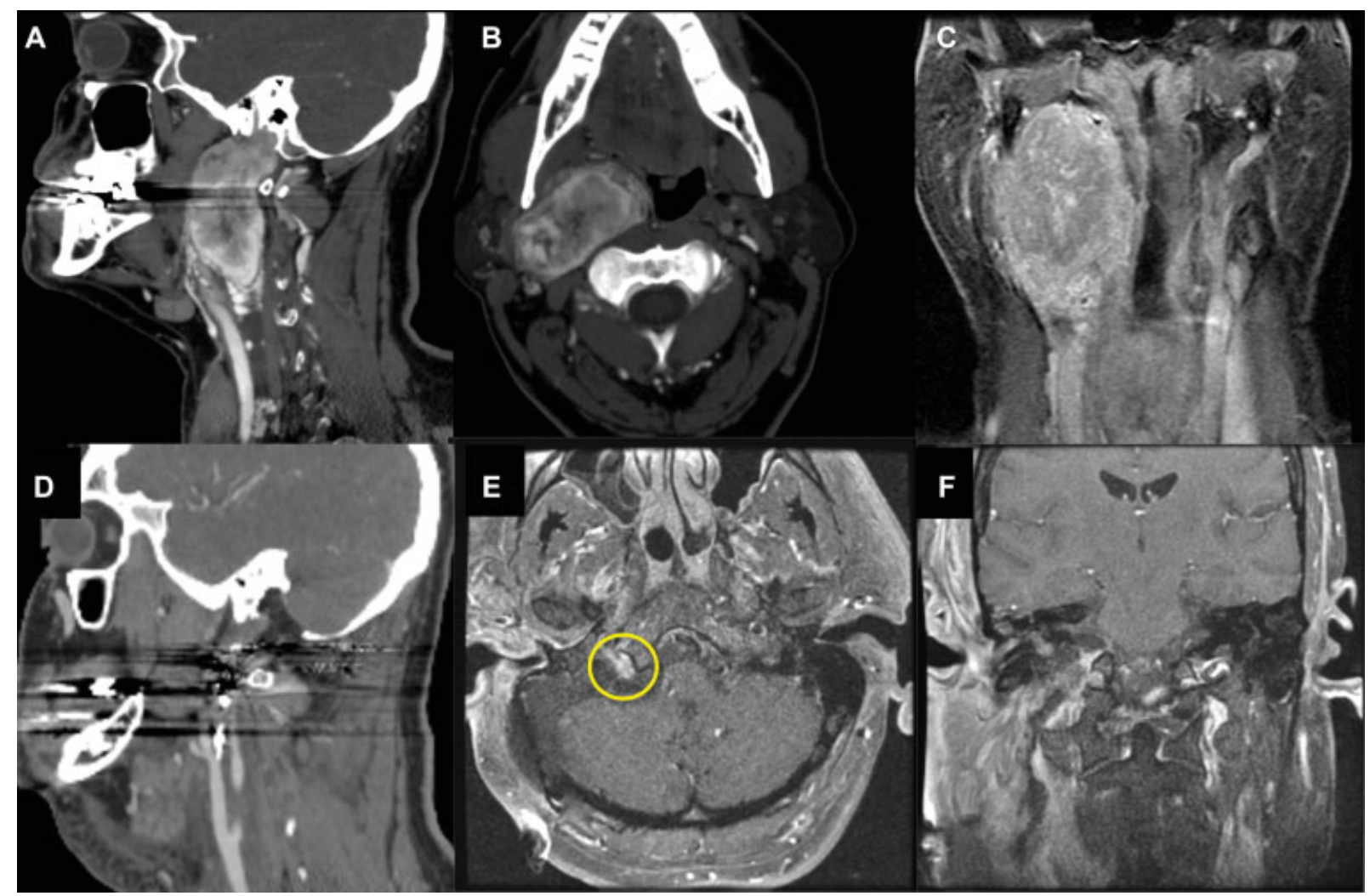

Fig. 1 Preoperative imaging. (A) Sagittal CT angiogram, (B) axial CT angiogram, and (C) coronal postgadolinium T1-weighted MRI show a large enhancing glomus vagale tumor in the parapharyngeal space extending from $\mathrm{C} 3$ to the jugular foramen. The internal and external carotid arteries are displaced anteriorly and the trachea is deviated medially. The tumor was resected using an extended anterolateral infralabyrinthine transjugular approach and a near-total resection was achieved. Postoperative imaging. (D) Sagittal CT angiogram, (E) axial postgadolinium T1weighted MRI, (F) coronal postgadolinium T1-weighted MRI shows near total resection of the tumor with a small enhancing residual at the pars nervosa (circle in $\mathrm{E})$. $\mathrm{CT}$, computed tomography; MRI, magnetic resonance imaging.

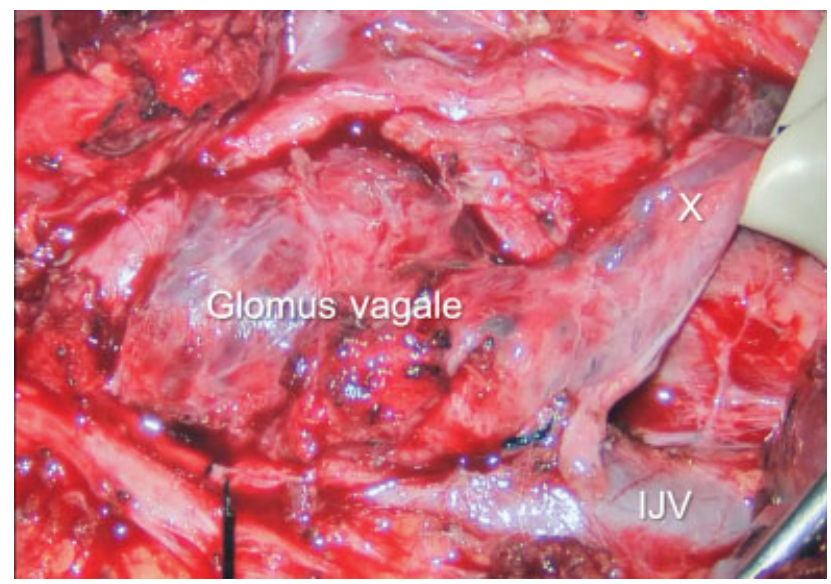

Fig. 2 Intraoperative photograph of a large glomus vagale tumor in the parapharyngeal space. X, vagus nerve; IJV, internal jugular vein. 